\title{
Current Role of Lipoprotein Apheresis
}

\author{
Gilbert Thompson $^{1} \cdot$ Klaus G. Parhofer ${ }^{2}$
}

Published online: 1 May 2019

(C) The Author(s) 2019

\begin{abstract}
Purpose of Review Lipoprotein apheresis is a very efficient but time-consuming and expensive method of lowering levels of lowdensity lipoprotein cholesterol, lipoprotein(a)) and other apoB containing lipoproteins, including triglyceride-rich lipoproteins. First introduced almost 45 years ago, it has long been a therapy of "last resort" for dyslipidaemias that cannot otherwise be managed. In recent years new, very potent lipid-lowering drugs have been developed and the purpose of this review is to define the role of lipoprotein apheresis in the current setting.

Recent Findings Lipoprotein apheresis still plays an important role in managing patients with homozygous $\mathrm{FH}$ and some patients with other forms of hypercholesterolaemia and cardiovascular disease. In particular, patients not achieving treatment goals despite modern lipid-lowering drugs, either because these are not tolerated or the response is insufficient. Recently, lipoprotein(a) has emerged as an important cardiovascular risk factor and lipoprotein apheresis has been used to decrease lipoprotein(a) concentrations in patients with marked elevations and cardiovascular disease. However, there is considerable heterogeneity concerning the recommendations by scientific bodies as to which patient groups should be treated with lipoprotein apheresis. Summary Lipoprotein apheresis remains an important tool for the management of patients with severe drug-resistant dyslipidaemias, especially those with homozygous FH.
\end{abstract}

Keywords Homozygous familial hypercholesterolaemia · Heterozygous familial hypercholesterolaemia Lipoprotein(a) · Apheresis guidelines

\section{Introduction}

A detailed description of the history and development of the extracorporeal removal of plasma cholesterol was published in a previous issue of Current Atherosclerosis Reports [1]. This introduction provides a brief account of the evolution over the past 50 years of the various procedures now collectively termed lipoprotein apheresis.

This article is part of the Topical Collection on Nonstatin Drugs

Gilbert Thompson

g.thompson@imperial.ac.uk

Klaus G. Parhofer

Parhofer@med2.med.uni-muenchen.de

1 Department of Metabolic Medicine, Imperial College London, Hammersmith Hospital, Ducane Road, London W12 0NN, UK

2 Medical Dept. IV - Grosshadern, Ludwig-Maximilians-University Munich, Munich, Germany
The initial stimulus to undertake a radical approach to lowering plasma cholesterol was the intractable nature and severity of the increase in low-density lipoprotein (LDL) cholesterol that characterised homozygous familial hypercholesterolaemia $(\mathrm{FH})$ and resulted all too often in premature death from atherosclerotic cardiovascular disease. The only LDLlowering drugs available in the 1960 s, nicotinic acid and cholestyramine, were ineffective in this situation so Myant [2] and De Gennes et al. [3] resorted to manual plasmapheresis. This lowered plasma cholesterol but was too slow and labour intensive for prolonged use. However, in 1975, Thompson et al. [40•] overcame these drawbacks by using a continuous flow blood cell separator to repetitively undertake unselective plasma exchange in $2 \mathrm{FH}$ homozygotes. Subsequently, Stoffel et al. [5*0] introduced selective removal of LDL by using a cell separator to perfuse plasma through an immunoadsorbent column. The latter procedure is still available [6] but has been largely superseded by methods involving perfusion of plasma or whole blood through affinity columns containing either dextran sulphate covalently linked to cellulose beads [7-9] or polyacrylate-coated polyacrylamide beads [10]. Like 
immunoapheresis, these bind the apolipoprotein B component of LDL and lipoprotein(a) (Lp(a)) and thus remove from the circulation these lipoproteins and their cargo of cholesterol.

A radically different approach to lipoprotein apheresis involves the extracorporeal precipitation of LDL through the addition of heparin to plasma, the so-called HELP system [11]. Precipitation of LDL occurs without addition of cations if the $\mathrm{pH}$ is lowered sufficiently, the precipitate being removed by filtration. Another method of removing lipoproteins from plasma is double filtration plasmapheresis (DFPP) $[12,13]$. In this procedure, plasma is separated from blood cells by a hollow membrane filter and then perfused through a second filter which selectively retains smaller plasma components like highdensity lipoprotein (HDL) and albumin, but discards larger molecular weight components including LDL and Lp(a).

Acute decreases in LDL-cholesterol after each procedure range from 60 to $80 \%$, depending upon the volume of blood or plasma treated. Although it lowers LDL-cholesterol to a similar extent, DFPP removes more HDL cholesterol than other methods. Haemoperfusion systems are the easiest to use but, like dextran sulphate-based plasma adsorption methods, employ disposable columns and are therefore more expensive than immunoadsorption, which utilises re-usable columns. Dextran sulphate-based methods are probably the most popular and are remarkably safe [14]. A comparison in FH homozygotes of dextran sulphate adsorption and HELP apheresis in Canada showed that the former lowered LDL-cholesterol to a greater extent than the latter $(70.5 \%$ vs $63 \%, P=0.02)$ mainly because it enables a greater volume of plasma to be treated [15].

A recent international survey of the management of $\mathrm{FH}$ found that lipoprotein apheresis was available in approximately $60 \%$ of 63 countries worldwide [16], cost being a limiting factor. In Germany, where lipoprotein apheresis is reimbursed by the health care system, almost 1300 patients received this treatment at 68 centres between 2012 and 2015 [17]. The clinical indications, current guidelines and evidence base for the efficacy of lipoprotein apheresis in the treatment of patients with severe hyperlipidaemia are discussed in the subsequent sections of this review.

\section{Current Indications and Recent Guidelines for Lipoprotein Apheresis}

Although most lipid guidelines mention lipoprotein apheresis as a therapy of last resort, they differ significantly in defining which patients to treat and under what circumstances [18]. This reflects a lack of convincing outcome trials as most of the evidence supporting the use of lipoprotein apheresis comes from retrospective analyses or extrapolation of intervention studies using lipid-lowering drugs. Since lipoprotein apheresis effectively decreases the plasma concentration of LDL, lipoprotein(a) and triglyceride-rich lipoproteins, it can be hypothesised that lipoprotein apheresis could be used in a number of different clinical settings.

Currently, lipoprotein apheresis is mainly used in two different clinical settings (Table 1):

- Significantly elevated LDL-cholesterol

- Significantly elevated lipoprotein(a)

With respect to elevated LDL-cholesterol (LDL-C), there is agreement that patients with homozygous $\mathrm{FH}$ inadequately responsive or refractory to lipid-lowering drugs qualify for such treatment [19-25]. Guidelines also agree that in homozygous FH, apheresis therapy should be started as early as possible, preferably in early childhood.

The situation is less clear-cut for patients with heterozygous FH or other forms of hypercholesterolaemia (Table 1). For example, in the USA, apheresis is approved for severe LDLhypercholesterolaemia which persists despite maximal drug therapy (LDL > $300 \mathrm{mg} / \mathrm{dl}(7.8 \mathrm{mmol} / \mathrm{L})$ without concomitant cardiovascular disease or $>200 \mathrm{mg} / \mathrm{dl}(5.2 \mathrm{mmol} / \mathrm{L})$ with concomitant cardiovascular disease) [20]. In Germany, apheresis for elevated LDL-C can be performed if, despite maximal possible drug therapy, LDL-C cannot be reduced sufficiently. No specific threshold is given because the overall risk profile of each patient needs to be considered [22]. In Japan, apheresis is indicated in heterozygous $\mathrm{FH}$ if total cholesterol remains above $250 \mathrm{mg} / \mathrm{dl}$ (6.5 mmol/L) despite maximal drug therapy [21]. Thus, generally speaking, apheresis can be considered in hypercholesterolaemia other than homozygous $\mathrm{FH}$ if atherosclerotic vascular disease is present and progressive and if LDL-C treatment goals, which vary from country to country, are not met despite maximal possible drug therapy (including proprotein convertase subtilisin/ kexin type 9 (PCSK9) inhibitors).

Although lipoprotein(a) is a causal risk factor for atherosclerotic disease and although there are only limited means to treat elevated lipoprotein(a) (Lp(a)) levels, the role of lipoprotein apheresis in this context is not well defined. The National Lipid Association and Heart-UK consider elevated Lp(a) as an additional risk factor that should be taken into account when deciding whether lipoprotein apheresis should be used to treat elevated LDL-C [20]. Elevated Lp(a) per se is therefore not an indication. In contrast, in Germany, elevated Lp(a) levels are considered to be an indication for regular apheresis if certain prerequisites are fulfilled, namely if $\mathrm{Lp}(\mathrm{a})$ is $>60 \mathrm{mg} / \mathrm{dl}$ in patients with progressive cardiovascular disease despite optimal management of all other risk factors including LDL-C [17]. Some of the other guidelines do not mention the role of lipoprotein apheresis for treating patients with elevated $\mathrm{Lp}(\mathrm{a})$.

Although lipoprotein apheresis also decreases the concentration of triglyceride-rich lipoproteins, none of the guidelines specify the circumstances under which hypertriglyceridaemia should be treated with lipoprotein apheresis. 
Table 1 Guidelines for using lipoprotein apheresis

\begin{tabular}{|c|c|}
\hline Country & Recommendation \\
\hline USA & $\begin{array}{l}\text { - Homozygous FH: LDL-c } \geq 500 \mathrm{mg} / \mathrm{dl}(12.9 \mathrm{mmol} / \mathrm{L}) \\
\text { on maximal possible drug therapy } \\
\text { - Heterozygous FH: LDL-c } \geq 300 \mathrm{mg} / \mathrm{dl}(7.8 \mathrm{mmol} / \mathrm{L}) \\
(0-1 \text { additional risk factor), LDL-c } \geq 200 \mathrm{mg} / \mathrm{dl} \\
(5.2 \mathrm{mmol} / \mathrm{L})(\geq 2 \text { additional risk factors or additional } \\
\text { high lipoprotein(a)), LDL } \geq 160 \mathrm{mg} / \mathrm{dl}(4.1 \mathrm{mmol} / \mathrm{L}) \\
\text { (if at very high risk) }\end{array}$ \\
\hline Germany & $\begin{array}{l}\text { - Homozygous FH } \\
\text { - Severe hypercholesterolaemia (including but not restricted } \\
\text { to heterozygous FH): LDL-c elevated on maximal } \\
\text { possible drug therapy (taking the overall risk of the } \\
\text { patient into account) } \\
\text { - Lipoprotein(a): progressive CVD } \\
\text { (clinically and on imaging) despite optimal control of all } \\
\text { other risk factors and lipoprotein(a) } \geq 60 \mathrm{mg} / \mathrm{dl}\end{array}$ \\
\hline Japan & $\begin{array}{l}\text { - Homozygous FH } \\
\text { - Heterozygous FH: total cholesterol } \geq 250 \mathrm{mg} / \mathrm{dl} \\
\quad(6.5 \mathrm{mmol} / \mathrm{L}) \text { on maximal possible drug therapy }\end{array}$ \\
\hline UK & $\begin{array}{l}\text { - Homozygous FH: LDL-c reduction }<50 \% \text { on max. drug } \\
\text { therapy or LDL-c } \geq 350 \mathrm{mg} / \mathrm{dl}(9.1 \mathrm{mmol} / \mathrm{L}) \\
\text { - Other hypercholesterolaemia (including heterozygous FH) } \\
\text { CVD progression and LDL-c } \geq 190 \mathrm{mg} / \mathrm{dl}(4.9 \mathrm{mmol} / \mathrm{L}) \\
\text { or lower if lipoprotein }(\mathrm{a}) \text { elevated or LDL-c } \\
\text { reduction }<40 \%\end{array}$ \\
\hline Australia & $\begin{array}{l}\text { - Homozygous FH: LDL-c } \geq 270 \mathrm{mg} / \mathrm{dl}(7.0 \mathrm{mmol} / \mathrm{L}) \text { on } \\
\text { maximal possible drug therapy } \\
\text { - Heterozygous FH: CVD and LDL-c } \geq 193 \mathrm{mg} / \mathrm{dl} \\
(5.0 \mathrm{mmol} / \mathrm{L}) \text { on maximal possible drug therapy } \\
\text { - Alternative criteria (homozygous FH and } \\
\text { heterozygous } \mathrm{FH}):<50 \% \text { reduction on maximal possible } \\
\text { drug therapy }\end{array}$ \\
\hline Spain & $\begin{array}{l}\text { - Homozygous FH } \\
\text { - Heterozygous FH: LDL-c } \geq 200 \mathrm{mg} / \mathrm{dl}(5.2 \mathrm{mmol} / \mathrm{L}) \text { with } \\
\text { CVD or } \geq 300 \mathrm{mg} / \mathrm{dl}(7.8 \mathrm{mmol} / \mathrm{L}) \text { without CVD }\end{array}$ \\
\hline
\end{tabular}

$C V D$ cardiovascular disease, $L D L-c$ LDL-cholesterol, $F H$ familial hypercholesterolaemia

\section{Theoretical and Practical Considerations Governing the Optimum Frequency and Efficacy of Lipoprotein Apheresis Procedures}

It has long been accepted that the production rate of LDL, the lipoprotein that transports over $90 \%$ of plasma cholesterol in FH homozygotes, obeys zero order kinetics, i.e. it remains constant irrespective of pool size, whereas catabolism of LDL is governed by first-order kinetics, i.e. the fractional catabolic rate (FCR) is constant irrespective of pool size [26]. There is a steep fall in plasma total and LDLcholesterol immediately after apheresis and then a curvelinear rebound back to the baseline level, the speed of which is largely determined by the FCR of the lipoprotein particle in question. For LDL, this depends upon inherent LDL receptor activity plus the influence of any lipid-lowering drugs on the latter, such as statins.
The magnitude of the acute decrease in lipoproteins after apheresis depends upon the volume of plasma treated, treatment of 1.2 plasma volumes (approximately 41 ) resulting in a reduction of $70 \%$ below the baseline value. As shown in Fig. 1, the subsequent rebound in plasma cholesterol is fastest in normal subjects and slowest in FH homozygotes, with heterozygotes intermediate. The actual value of total or LDLcholesterol $(\mathrm{Ct})$ at any given time ( $\mathrm{t}$ ) after apheresis can be calculated from the formula:

$\mathrm{Ct}=\mathrm{C} 0-(\mathrm{C} 0-\mathrm{Cmin}) \mathrm{e}^{-\mathrm{kt}}$

where $\mathrm{C} 0$ is the baseline value, $\mathrm{Cmin}$ is the post-apheresis value, and $\mathrm{k}$ is the FCR [27]. For example, in the homozygote in Fig. 1, if the baseline level of cholesterol of $15 \mathrm{mmol} / \mathrm{l}$ is acutely reduced by $70 \%$ and the FCR is 0.1 , the post-apheresis levels at 1 and 2 weeks will be respectively $35 \%$ and $17 \%$ below the baseline level. Similarly in the heterozygote, if the baseline level of $7 \mathrm{mmol} / \mathrm{l}$ is reduced by $70 \%$ and the FCR is 0.2 , then post-apheresis levels at 1 and 2 weeks will be $17 \%$ and $4 \%$ below the baseline level. Hence, apheresis every 2 weeks has a modest cholesterol-lowering effect in homozygotes but virtually none in heterozygotes, in whom weekly apheresis is necessary for any significant effect. This is exemplified by the Familial Hypercholesterolaemia Regression Study, where bi-weekly apheresis (because of operational constraints) plus simvastatin lowered LDL-cholesterol only marginally more in $\mathrm{FH}$ heterozygotes than did a bile acid sequestrant plus simvastatin [28].

A similar approach can be used to describe $L p(a)$ rebound following apheresis. A direct comparison indicates that lipoprotein(a) rebounds at a slower rate than LDL but with a similar monoexponential function [29]. Therefore, if apheresis is performed weekly, $\mathrm{Lp}$ (a) concentration will not rebound to its original (pre-first apheresis) value and therefore, a lower level will be achieved.

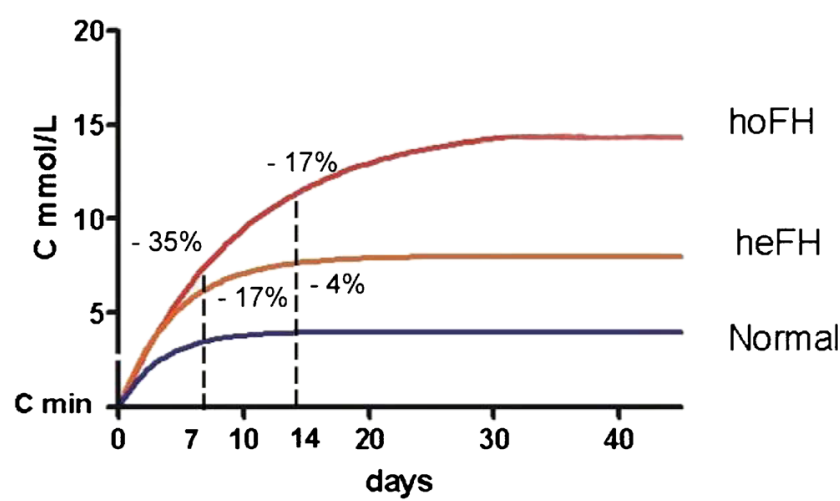

Fig. 1 Rebounds in plasma cholesterol (C) from post-apheresis values (C $\mathrm{min})$ are shown in a normal subject, $\mathrm{FH}$ heterozygote (heFH) and $\mathrm{FH}$ homozygote (hoFH). Values of $\mathrm{C}$ expressed as percentages of baseline values in FH patients are shown at 7 and 14 days, illustrating the reductions achieved by weekly versus bi-weekly apheresis respectively 
Plasma levels of LDL and Lp(a) decrease further if apheresis is repeated on a regular basis but stabilise when a new non-steady state is reached. In terms of clinical relevance, the best index of efficacy is probably the interval mean between successive procedures, which can be calculated by integrating the area under the rebound curve or using a modified version of the formula of Kroon et al. [30, 31]. Patients' compliance is another important factor in determining the long-term benefit of lipoprotein apheresis. A recent survey in France showed an overall compliance rate of nearly $90 \%$, non-compliance being evident mainly in patients undergoing weekly apheresis [32].

\section{Recent Evidence of Therapeutic Benefit of Lipoprotein Apheresis via Lowering of}

\section{a. Low-Density Lipoprotein}

Data from the German Lipoprotein Apheresis Registry (GLAR), based on over 15,000 apheresis procedures, showed a median acute reduction in LDL-cholesterol of $69 \%$ and of $\mathrm{Lp}(\mathrm{a})$ of $70 \%$ in hyperlipidaemic patients with cardiovascular disease [17]. These reductions were associated with a 97\% decrease in the incidence of major adverse coronary events (MACE) during the first year of lipoprotein apheresis compared with the 2 years preceding the start of this treatment. These data were obtained prior to the introduction of PCSK9 inhibitors in Germany.

In the ODYSSEY ESCAPE trial, treatment of FH heterozygotes undergoing lipoprotein apheresis with the PCSK9 inhibitor alirocumab resulted in an additional $54 \%$ reduction in LDL-cholesterol. Based on the trial criterion of reducing LDL-cholesterol by $\geq 30 \%$ below the baseline value on apheresis, $63 \%$ of patients on alirocumab were able to discontinue apheresis altogether and over $90 \%$ to halve its frequency [33••]. In contrast, in FH homozygotes on apheresis in the TAUSSIG study, reductions in LDL-cholesterol after the addition of the PCSK9 inhibitor evolocumab averaged 23\% [34-]. This was much less than that observed in FH heterozygotes on evolocumab [35] and the decrease in $\mathrm{Lp}(\mathrm{a})$ was also less, only $12 \%$.

One of the factors influencing the LDL-lowering response of homozygotes to evolocumab was LDL receptor status. The $10 \%$ who were receptor negative showed only a $6 \%$ decrease in LDL whereas those who were receptor defective had a $24 \%$ decrease. Although PCSK9 inhibitors clearly have considerable potential as an alternative to apheresis in the treatment of patients with statin-refractory heterozygous $\mathrm{FH}$, their usefulness in homozygous $\mathrm{FH}$ and in patients with raised $\mathrm{Lp}$ (a) levels is less obvious and in most instances, they will complement rather than replace lipoprotein apheresis.

Another adjunctive drug, whose action is independent of LDL receptor status, is the microsomal triglyceride transfer protein (MTP) inhibitor lomitapide, which reduces LDLcholesterol by $50 \%$ in FH homozygotes [36]. Its efficacy is similar irrespective of whether such patients are or are not on lipoprotein apheresis and in about $50 \%$ of instances, it reduced their LDL-cholesterol to $<2.5 \mathrm{mmol} / 1(96 \mathrm{mg} / \mathrm{dl})$ [37]. However, its long-term safety remains under scrutiny. The apoB synthesis inhibitor mipomersen was used in another study in patients undergoing regular apheresis but did not result in a decreased apheresis frequency and was associated with a high incidence of side effects [38].

A frequent cause of morbidity and mortality in homozygous FH is atherosclerosis of the aortic root. The location and severity of atheroma at this site in FH homozygotes, but not in heterozygotes, is identical to that seen in cholesterol-fed rabbits and is attributable to the severity of hypercholesterolaemia in both these situations [39]. A 50-year long survey of UK patients found that the occurrence of aortic stenosis was lower in patients who started treatment during the 1990s as opposed to those treated in the pre-statin era (33\% vs $77 \%, P=0.02)$, reflecting better control of serum cholesterol by apheresis and statins [40]. A French study of children with homozygous FH showed that the frequency of aortic stenosis and need for surgery were associated with the age at which lipoprotein apheresis was initiated [41]. Those with aortic root atheroma started apheresis at age 10 whereas those without atheroma had started it earlier, at age 5 .

Recent evidence that effective lipid-lowering therapy increases life expectancy came from a retrospective survey of 133 homozygotes in South Africa and the UK who were divided into quartiles according to their on-treatment levels of serum cholesterol from 1990 to 2014 [42•]. Patients in quartile 4 , with an on-treatment serum cholesterol $>15 \mathrm{mmol} / 1$ $(584 \mathrm{mg} / \mathrm{dl})$, had a hazard ratio of 11:5 for total mortality compared with those in quartile 1 , with an on-treatment cholesterol of $<8 \mathrm{mmol} / \mathrm{l}(313 \mathrm{mg} / \mathrm{dl})$. Those in quartiles 2 and 3 combined, with an on-treatment cholesterol of $8(313 \mathrm{mg} / \mathrm{dl})$ $-15 \mathrm{mmol} / \mathrm{l}(584 \mathrm{mg} / \mathrm{dl})$, had a hazard ratio of $3: 6$ compared with quartile 1 . These differences were statistically significant $(P<0.001)$ and remained so after adjustments for confounding factors $(P=0.04)$. Significant differences between quartiles were also evident for cardiovascular deaths and MACE. It is noteworthy that $50 \%$ of UK patients were on apheresis versus $13 \%$ of South African patients and that $60 \%$ of the former but only $19 \%$ of the latter were in quartile 1 , reflecting the fact that reductions in total cholesterol in patients on apheresis averaged 57\% in the UK versus 32\% in South Africa $(P=0.01)$. This study provides strong evidence that the extent of reduction of serum cholesterol achieved by a combination of therapeutic measures, including lipoprotein apheresis, statins, ezetimibe, and evolocumab, is a major determinant of survival in homozygous FH. As stated in an accompanying editorial, at long last, there is "light at the end of the tunnel" for homozygous FH [43]. 


\section{Recent Evidence of Therapeutic Benefit of Lipoprotein Apheresis via Lowering of}

\section{b. Lipoprotein(a)}

An elevated Lp(a) level is an independent risk factor for atherosclerosis [44]. Thus, it can be expected that lowering $\mathrm{Lp}$ (a) levels translates into clinical benefit. It is however unclear how much Lp(a) must be decreased to achieve significant risk reduction. In a recent study based on genetic data, it was hypothesised that a decrease in $\mathrm{Lp}$ (a) concentration of $>$ $100 \mathrm{mg} / \mathrm{dl}$ is required to achieve a benefit equivalent to $1 \mathrm{mmol} / 1$ (39 mg/dl) of LDL-cholesterol lowering [45]. On the other hand, data from the Odyssey Outcomes trial indicate that much less reduction in $\mathrm{Lp}$ (a) was beneficial $(1 \mathrm{mg} / \mathrm{dl}$ reduction resulted in $0.6 \%$ relative risk reduction; thus, about $35 \mathrm{mg} / \mathrm{dl}$ lipoprotein(a) reduction would lead to the same risk reduction as $1 \mathrm{mmol} / \mathrm{L}$ (39 $\mathrm{mg} / \mathrm{dl})$ of LDL-C reduction) [data only published in abstract form]. The topic is further complicated by the fact that so far there are no drugs available that solely decrease Lp(a) concentrations. Niacin decreases Lp(a) but has also multiple other effects on lipoproteins and was not shown to have clinical benefit [46]. PCSK9 inhibitors can also decrease $\mathrm{Lp}$ (a) concentrations but also (and primarily) decrease LDL-cholesterol, which makes it difficult to decide how much of the clinical benefit relates to LDL-cholesterol reduction and how much to lipoprotein(a) reduction. Similarly, most lipoprotein apheresis methods decrease both LDL and Lp(a) concentrations, again making it difficult to dissect out the effect of lipoprotein(a) reduction. In addition, there are no adequate clinical endpoint trials evaluating the effect of apheresis in patients with elevated Lp(a).

As discussed earlier, an older trial evaluated whether in patients with CAD and heterozygous FH $(n=39)$ bi-weekly apheresis in combination with simvastatin (40 mg/day) is superior to simvastatin (40 $\mathrm{mg} /$ day) in combination with colestipol (20 g/day) [28]. After 2.1 years, there was no significant difference between the two groups and therefore, the authors concluded that "decreasing Lp(a) seems to be unnecessary if LDL-C is reduced to $3.4 \mathrm{mmol} / 1$ (132 mg/dl) or less". However, patients had a low Lp(a) baseline level and only a modest $\mathrm{Lp}(\mathrm{a})$ reduction with apheresis (mean reduction $10 \mathrm{mg} / \mathrm{dl}$ ). In a subsequent angiographic trial, it was evaluated whether a specific Lp(a) apheresis (Lipopac apheresis) plus statin reduces CHD progression compared to statin alone in 30 patients with CHD and elevated lipoprotein(a) (>50 mg/dl) [47]. After 18 months, apheresis-treated patients showed significantly more regression and less progression. Again, this trial was limited by a small number of subjects and the lack of reporting of clinical events.

Recently, an analysis of the German Lipoprotein Apheresis Registry for the period 2012-2015 was reported and showed acute reductions of LDL-cholesterol and $\mathrm{Lp}(\mathrm{a})$ of $68.6 \%$ and
$70.4 \%$ respectively [17]. The data showed a dramatic reduction $(-97 \%)$ of cardiovascular events when the period before initiation of apheresis was compared to the period of regular apheresis. This very impressive reduction must be interpreted with caution as the setting is not randomised or controlled. Another publication showed significant reduction of interventions in patients with peripheral artery disease after initiation of apheresis (observational data) [48].

This recent analysis confirms previous German evaluations and also a study from Italy evaluating cardiovascular events before initiation of apheresis and during regular apheresis therapy [49, 50•, 51, 52]. In two of the German studies, only subjects with isolated $\mathrm{Lp}$ (a) elevation were included (with LDL $<2.5 \mathrm{mmol} / 1(97 \mathrm{mg} / \mathrm{dl})$ on statin therapy) [51, 52], while in the third study, patients with concomitantly elevated LDL-cholesterol were also included [50•]. The event rate decreased in all 4 studies dramatically after initiation of regular apheresis but these observations are severely limited by the lack of a control group. Progression of disease and recurrent events are the main reasons for starting a patient on apheresis. Thus, it is not surprising to observe a very high event rate in the time period before regular apheresis. As outlined elsewhere, it is impossible to confirm the true effect of apheresis without an adequate control group [53, 54].

\section{Recent Evidence of Therapeutic Benefit of Lipoprotein Apheresis via Lowering of}

\section{c. Triglyceride-Rich Lipoproteins}

Severe hypertriglyceridaemia (> $10 \mathrm{mmol} / \mathrm{l}$; ca $900 \mathrm{mg} / \mathrm{dl}$ ) due to increased levels of very low-density lipoprotein (VLDL), chylomicrons and remnant particles is a recognised cause of acute pancreatitis. In these circumstances, plasma exchange with a centrifugal cell separator enables triglyceride levels to be drastically reduced with a rapid resolution of abdominal pain [55]. Hitherto there has been no evidence that this approach reduces morbidity and mortality [56] but recently, Chang et al. [57] showed that in patients with extreme hypertriglyceridaemia (> $56 \mathrm{mmol} / \mathrm{l}$; ca $4900 \mathrm{mg} / \mathrm{dl}$ ) and acute pancreatitis, treatment with DFPP halved the duration of hospitalisation compared with patients receiving conventional therapy. However, it remains uncertain whether apheresis can reduce mortality in this situation [58].

\section{Future Prospects for Lipoprotein Apheresis in the Light of Recent Advances in Lipid-Lowering Drugs}

Lipoprotein apheresis is not only a modality that has enabled patients with severe hypercholesterolaemia and elevated 
lipoprotein(a) to be treated but it has also been used as a tool for the better understanding of the regulatory processes involved in lipoprotein metabolism and has thereby advanced knowledge [29, 59-62].

In recent years, new drugs have been brought to the market that effectively treat many patients with severe hypercholesterolemia without resorting to apheresis. The availability of PCSK9 inhibitors decreases the necessity for apheresis dramatically as most patients with heterozygous FH and other forms of hypercholesterolaemia respond very well to this therapy [33••]. From the "LDL-perspective", only patients with homozygous $\mathrm{FH}$ and a limited number of patients with severe forms of heterozygous FH or patients intolerant to any form of lipid-lowering drugs remain potential candidates. With further drugs such as ANGPTL3 inhibitors and bempedoic acid being developed, this group may decrease further [63].

Similarly, potent drugs are being developed for decreasing $\mathrm{Lp}(\mathrm{a})$. Of particular interest is an antisense oligo nucleotide that can decrease Lp(a) by more than $70 \%$, which is much greater than the observed interval mean reduction during regular apheresis [64•]. Assuming safety, it can be anticipated that these drugs will have a similar effect on apheresis for elevated Lp(a) as had PCSK9 inhibitors on apheresis for elevated LDLcholesterol and they will eventually further decrease the number of patients requiring apheresis.

However, we should keep one thing in mind: patients treated by regular apheresis have the advantage of being seen by the same medical team on a very regular (weekly or biweekly) basis. This tight control and guidance improves compliance (generally speaking) and allows medical issues to be discussed regularly in a familiar setting. Although this effect is hard to quantify, it would be surprising if it did not also affect the cardiovascular event rate. Obviously, drug therapy gives the patient more "freedom" but maybe at the cost of less strict medical surveillance.

\section{Conclusions}

Even after recent dramatic improvements in drugs affecting lipid metabolism, lipoprotein apheresis still has its role in treating patients with certain dyslipidaemias. While most patients with heterozygous FH or other forms of elevated LDLcholesterol can now be treated with drugs, apheresis remains a therapy of last resort in those not responding or intolerant to drugs and is still the gold standard for patients with homozygous FH. It is not only very efficient in decreasing LDLcholesterol but also very safe and, unlike lomitapide, it can be used in children. In addition to its role in treating severe forms of LDL-hypercholesterolaemia, it is also used in patients with severe elevations of $\mathrm{Lp}(\mathrm{a})$ and atherosclerotic disease, although its role in this situation is less well defined. While the number of patients requiring apheresis will probably decrease as new drugs are developed, it will remain a therapy to be kept in reserve for certain types of patient.

\section{Compliance with Ethical Standards}

Conflict of Interest Gilbert Thompson declares no conflict of interest. Dr. Parhofer reports personal fees from Aegerion, Akcea, Amgen, Boehringer-Ingelheim, and MSD. Dr. Parhofer also reports grants from Novartis, grants and personal fees from Regeneron, grants and personal fees from Sanofi, all outside of the selected work.

Human and Animal Rights and Informed Consent This article does not contain any studies with human or animal subjects performed by any of the authors.

Open Access This article is distributed under the terms of the Creative Commons Attribution 4.0 International License (http:// creativecommons.org/licenses/by/4.0/), which permits unrestricted use, distribution, and reproduction in any medium, provided you give appropriate credit to the original author(s) and the source, provide a link to the Creative Commons license, and indicate if changes were made.

\section{References}

Papers of particular interest, published recently, have been highlighted as:

- Of importance

-• Of major importance

1. Stefanutti C, Thompson GR. Lipoprotein apheresis in the management of familial hypercholesterolaemia: historical perspective and recent advances. Curr Atheroscler Rep. 2015;17:465.

2. Myant NB. Plasma cholesterol as a cause of coronary heart disease (CHD); the cholesterol - CHD hypothesis. In: Reynolds LM, editor. Wellcome witnesses to twentieth century medicine, vol. 27. London: The Wellcome Trust; 2006.

3. de Gennes JL, Touraine R, Maunand B, Truffert J, Laudat P. [Homozygous cutaneo-tendinous forms of hypercholesteremic xanthomatosis in an exemplary familial case. Trial of plasmapheresis an heroic treatment]. Bull Mem Soc Med Hop Paris. 1967;118: 1377-402.

4.• Thompson GR, Lowenthal R, Myant NB. Plasma exchange in the management of homozygous familial hypercholesterolaemia. Lancet. 1975;1:1208-11 First report demonstrating that cholesterol can be lowered by extracorporeal treatment modality. The study also included ${ }^{14} \mathrm{C}$ - cholesterol turnover experiments, elucidating the pathway of cholesterol removal.

5.• Stoffel W, Borberg H, Greve V. Application of specific extracorporeal removal of low density lipoprotein in familial hypercholesterolaemia. Lancet. 1981;2:1005-7 First selective apheresis device to decrease LDL-cholesterol. The method is based on binding apoB containing lipoproteins to a column and thus eliminating LDL particles from plasma.

6. Richter WO, Jacob BG, Ritter MM, Suhler K, Vierneisel K, Schwandt P. Three-year treatment of familial heterozygous hypercholesterolemia by extracorporeal low-density lipoprotein immunoadsorption with polyclonal apolipoprotein B antibodies. Metabolism. 1993;42:888-94. 
7. Julius U, Parhofer KG, Heibges A, Kurz S, Klingel R, Geiss HC. Dextran-sulfate-adsorption of atherosclerotic lipoproteins from whole blood or separated plasma for lipid-apheresis-comparison of performance characteristics with DALI and lipid filtration. J Clin Apher. 2007;22:215-23.

8. Mabuchi H, Michishita I, Takeda M, Fujita H, Koizumi J, Takeda $\mathrm{R}$, et al. A new low density lipoprotein apheresis system using two dextran sulfate cellulose columns in an automated column regenerating unit (LDL continuous apheresis). Atherosclerosis. 1987;68:19-25.

9. Yokoyama S, Hayashi R, Satani M, Yamamoto A. Selective removal of low density lipoprotein by plasmapheresis in familial hypercholesterolemia. Arteriosclerosis. 1985;5:613-22.

10. Bosch T, Schmidt B, Blumenstein M, Gurland HJ. Lipid apheresis by hemoperfusion: in vitro efficacy and ex vivo biocompatibility of a new low-density lipoprotein adsorber compatible with human whole blood. Artif Organs. 1993;17:640-52.

11. Eisenhauer T, Armstrong VW, Wieland H, Fuchs C, Scheler F, Seidel D. Selective removal of low density lipoproteins (LDL) by precipitation at low $\mathrm{pH}$ : first clinical application of the HELP system. Klin Wochenschr. 1987;65:161-8.

12. Agishi T, Kaneko I, Hasuo Y, Hayasaka Y, Sanaka T, Ota K, et al. Double filtration plasmapheresis. Trans Am Soc Artif Intern Organs. 1980;26:406-11.

13. Klingel R, Mausfeld P, Fassbender C, Goehlen B. Lipidfiltrationsafe and effective methodology to perform lipid-apheresis. Transfus Apher Sci. 2004;30:245-54.

14. Gordon BR, Kelsey SF, Dau PC, Gotto AM Jr, Graham K, Illingworth DR, et al. Long-term effects of low-density lipoprotein apheresis using an automated dextran sulfate cellulose adsorption system. Liposorber Study Group. Am J Cardiol. 1998;81:407-11.

15. Drouin-Chartier JP, Tremblay AJ, Bergeron J, Pelletier M, Laflamme N, Lamarche B, et al. Comparison of two low-density lipoprotein apheresis systems in patients with homozygous familial hypercholesterolemia. J Clin Apher. 2016;31:359-67.

16. Collaboration EASFHS, Investigators EASFHSC. Overview of the current status of familial hypercholesterolaemia care in over 60 countries - The EAS Familial Hypercholesterolaemia Studies Collaboration (FHSC). Atherosclerosis. 2018;277:234-55.

17. Schettler VJ, Neumann CL, Peter C, Zimmermann T, Julius U, Roeseler E, et al. The German lipoprotein apheresis registry (GLAR) - almost 5 years on. Clin Res Cardiol Suppl. 2017;12(Suppl 1):44-9.

18. Wang A, Richhariya A, Gandra SR, Calimlim B, Kim L, Quek RG, et al. Systematic review of low-density lipoprotein cholesterol apheresis for the treatment of familial hypercholesterolemia. J Am Heart Assoc. 2016;5:e003294. https://doi.org/10.1161/JAHA.116. 003294.

19. Civeira F, International Panel on Management of Familial H. Guidelines for the diagnosis and management of heterozygous familial hypercholesterolemia. Atherosclerosis. 2004; 173:55-68.

20. Goldberg AC, Hopkins PN, Toth PP, Ballantyne CM, Rader DJ, Robinson JG, et al. Familial hypercholesterolemia: screening, diagnosis and management of pediatric and adult patients: clinical guidance from the National Lipid Association Expert Panel on Familial Hypercholesterolemia. J Clin Lipidol. 2011;5:133-40.

21. Harada-Shiba M, Arai H, Oikawa S, Ohta T, Okada T, Okamura T, et al. Guidelines for the management of familial hypercholesterolemia. J Atheroscler Thromb. 2012;19:1043-60.

22. Schettler V, Neumann CL, Hulpke-Wette M, Hagenah GC, Schulz EG, Wieland E, et al. Current view: indications for extracorporeal lipid apheresis treatment. Clin Res Cardiol Suppl. 2012;7:15-9.

23. Szczepiorkowski ZM, Winters JL, Bandarenko N, Kim HC, Linenberger ML, Marques MB, et al. Guidelines on the use of therapeutic apheresis in clinical practice-evidence-based approach from the Apheresis Applications Committee of the American Society for apheresis. J Clin Apher. 2010;25:83-177.
24. Thompson GR. Recommendations for the use of LDL apheresis. Atherosclerosis. 2008;198:247-55.

25. Watts GF, Gidding S, Wierzbicki AS, Toth PP, Alonso R, Brown $\mathrm{WV}$, et al. Integrated guidance on the care of familial hypercholesterolaemia from the International FH Foundation. Int J Cardiol. 2014;171:309-25.

26. Apstein CS, Zilversmit DB, Lees RS, George PK. Effect of intessive plasmapheresis on the plasma cholesterol concentration with familial hypercholesterolemia. Atherosclerosis. 1978;31:10515.

27. France M, Rees A, Datta D, Thompson G, Capps N, Ferns G, et al. HEART UK statement on the management of homozygous familial hypercholesterolaemia in the United Kingdom. Atherosclerosis. 2016;255:128-39.

28. Thompson GR, Maher VM, Matthews S, Kitano Y, Neuwirth C, Shortt MB, et al. Familial hypercholesterolaemia regression study: a randomised trial of low-density-lipoprotein apheresis. Lancet. 1995;345:811-6.

29. Ma L, Waldmann E, Ooi EMM, Chan DC, Barrett HPR, Watts GF, et al. Lipoprotein (a) and low-density lipoprotein apolipoprotein B metabolism following apheresis in patients with elevated lipoprotein(a) and coronary artery disease. Eur J Clin Investig. 2019;49:e13053.

30. Kroon AA, van't Hof MA, Demacker PN, Stalenhoef AF. The rebound of lipoproteins after LDL-apheresis. Kinetics and estimation of mean lipoprotein levels. Atherosclerosis. 2000;152:519-26.

31. Thompson GR, Barbir M, Davies D, Dobral P, Gesinde M, Livingston $\mathrm{M}$, et al. Efficacy criteria and cholesterol targets for LDL apheresis. Atherosclerosis. 2010;208:317-21.

32. Beliard S, Gallo A, Duchene E, Carrie A, Bittar R, Chapman MJ, et al. Lipoprotein-apheresis in familial hypercholesterolemia: longterm patient compliance in a French cohort. Atherosclerosis. 2018;277:66-71.

33.• Moriarty PM, Parhofer KG, Babirak SP, Cornier MA, Duell PB, Hohenstein B, et al. Alirocumab in patients with heterozygous familial hypercholesterolaemia undergoing lipoprotein apheresis: the ODYSSEY ESCAPE trial. Eur Heart J. 2016;37:3588-95 In this study it was shown that the PCSK9-inhibitor alirocumab can enable many patients with heterozygous $\mathrm{FH}$ to avoid apheresis.

34. Raal FJ, Hovingh GK, Blom D, Santos RD, Harada-Shiba M, Bruckert E, et al. Long-term treatment with evolocumab added to conventional drug therapy, with or without apheresis, in patients with homozygous familial hypercholesterolaemia: an interim subset analysis of the open-label TAUSSIG study. Lancet Diabetes Endocrinol. 2017;5:280-90 This study shows that the PCSK9inhibor evolocumab can decrease the frequency of apheresis in some patients with homozygous $\mathbf{F H}$.

35. Raal FJ, Stein EA, Dufour R, Turner T, Civeira F, Burgess L, et al. PCSK9 inhibition with evolocumab (AMG 145) in heterozygous familial hypercholesterolaemia (RUTHERFORD-2): a randomised, double-blind, placebo-controlled trial. Lancet. 2015;385:331-40.

36. Cuchel M, Meagher EA, du Toit Theron H, Blom DJ, Marais AD, Hegele RA, et al. Efficacy and safety of a microsomal triglyceride transfer protein inhibitor in patients with homozygous familial hypercholesterolaemia: a single-arm, open-label, phase 3 study. Lancet. 2013;381:40-6.

37. Stefanutti C, Blom DJ, Averna MR, Meagher EA, Theron H, Marais $\mathrm{AD}$, et al. The lipid-lowering effects of lomitapide are unaffected by adjunctive apheresis in patients with homozygous familial hypercholesterolaemia - a post-hoc analysis of a phase 3, single-arm, open-label trial. Atherosclerosis. 2015;240:408-14.

38. Waldmann E, Vogt A, Crispin A, Altenhofer J, Riks I, Parhofer KG. Effect of mipomersen on LDL-cholesterol in patients with severe LDL-hypercholesterolaemia and atherosclerosis treated by lipoprotein apheresis (the MICA-study). Atherosclerosis. 2017;259:20-5. 
39. Thompson GR. Atherosclerosis in cholesterol-fed rabbits and in homozygous and heterozygous LDL receptor-deficient humans. Atherosclerosis. 2018;276:148-54.

40. Thompson GR, Seed M, Naoumova RP, Neuwirth C, Walji S, Aitman TJ, et al. Improved cardiovascular outcomes following temporal advances in lipid-lowering therapy in a geneticallycharacterised cohort of familial hypercholesterolaemia homozygotes. Atherosclerosis. 2015;243:328-33.

41. Lefort B, Saheb S, Bruckert E, Giraud C, Hequet O, Hankard R. Impact of LDL apheresis on aortic root atheroma in children with homozygous familial hypercholesterolemia. Atherosclerosis. 2015;239:158-62.

42. Thompson GR, Blom DJ, Marais AD, Seed M, Pilcher GJ, Raal FJ. Survival in homozygous familial hypercholesterolaemia is determined by the on-treatment level of serum cholesterol. Eur Heart J. 2018;39:1162-8 Unequivocal demonstration that longevity in homozygous $\mathrm{FH}$ is determined by the extent of reduction in serum cholesterol achieved by the combination of apheresis and lipid-lowering drug therapy.

43. Stoekenbroek RM, Kees Hovingh G, Kastelein JJP. Homozygous familial hypercholesterolaemia: light at the end of the tunnel. Eur Heart J. 2018;39:1169-71.

44. Nordestgaard BG, Chapman MJ, Ray K, Boren J, Andreotti F, Watts GF, et al. Lipoprotein(a) as a cardiovascular risk factor: current status. Eur Heart J. 2010;31:2844-53.

45. Burgess S, Ference BA, Staley JR, Freitag DF, Mason AM, Nielsen SF, et al. Association of LPA variants with risk of coronary disease and the implications for lipoprotein(a)-lowering therapies: a Mendelian randomization analysis. JAMA Cardiol. 2018;3:61927.

46. Landray MJ, Haynes R, Hopewell JC, Parish S, Aung T, Tomson J, et al. Effects of extended-release niacin with laropiprant in high-risk patients. N Engl J Med. 2014;371:203-12.

47. Safarova MS, Ezhov MV, Afanasieva OI, Matchin YG, Atanesyan RV, Adamova IY, et al. Effect of specific lipoprotein(a) apheresis on coronary atherosclerosis regression assessed by quantitative coronary angiography. Atheroscler Suppl. 2013;14:93-9.

48. Poller WC, Berger A, Dreger H, Morgera S, Enke-Melzer K. Lipoprotein apheresis in patients with peripheral artery disease and lipoprotein(a)-hyperlipoproteinemia: 2-year follow-up of a prospective single center study. Atheroscler Suppl. 2017;30:174-9.

49. Bigazzi F, Sbrana F, Berretti D, Maria Grazia Z, Zambon S, Fabris A, et al. Reduced incidence of cardiovascular events in hyper-Lp(a) patients on lipoprotein apheresis. The G.I.L.A. (Gruppo Interdisciplinare Aferesi Lipoproteica) pilot study. Transfus Apher Sci. 2018;57:661-4.

50. Jaeger BR, Richter Y, Nagel D, Heigl F, Vogt A, Roeseler E, et al. Longitudinal cohort study on the effectiveness of lipid apheresis treatment to reduce high lipoprotein(a) levels and prevent major adverse coronary events. Nat Clin Pract Cardiovasc Med. 2009;6: 229-39 The first study that showed that the cardiovascular event rate decreases dramatically after initiation of regular apheresis of patients with raised $L p(a)$; although the reduction is impressive, the data must be interpreted with caution as the study lacks a control group.
51. Leebmann J, Roeseler E, Julius U, Heigl F, Spitthoever R, Heutling $\mathrm{D}$, et al. Lipoprotein apheresis in patients with maximally tolerated lipid-lowering therapy, lipoprotein(a)-hyperlipoproteinemia, and progressive cardiovascular disease: prospective observational multicenter study. Circulation. 2013;128:2567-76.

52. Rosada A, Kassner U, Vogt A, Willhauck M, Parhofer K, Steinhagen-Thiessen E. Does regular lipid apheresis in patients with isolated elevated lipoprotein(a) levels reduce the incidence of cardiovascular events? Artif Organs. 2014;38:135-41.

53. Waldmann E, Parhofer KG. Lipoprotein apheresis to treat elevated lipoprotein (a). J Lipid Res. 2016;57:1751-7.

54. Waldmann E, Parhofer KG. Apheresis for severe hypercholesterolaemia and elevated lipoprotein(a). Pathology. 2019;51:227-32.

55. Kyriakidis AV, Raitsiou B, Sakagianni A, Harisopoulou V, Pyrgioti M, Panagopoulou A, et al. Management of acute severe hyperlipidemic pancreatitis. Digestion. 2006;73(4):259-64.

56. Chen JH, Yeh JH, Lai HW, Liao CS. Therapeutic plasma exchange in patients with hyperlipidemic pancreatitis. World J Gastroenterol. 2004;10:2272-4.

57. Chang CT, Tsai TY, Liao HY, Chang CM, Jheng JS, Huang WH, et al. Double filtration plasma apheresis shortens hospital admission duration of patients with severe hypertriglyceridemia-associated acute pancreatitis. Pancreas. 2016;45:606-12.

58. Nakhoda S, Zimrin AB, Baer MR, Law JY. Use of the APACHE II score to assess impact of therapeutic plasma exchange for critically ill patients with hypertriglyceride-induced pancreatitis. Transfus Apher Sci. 2017;56:123-6.

59. Barrett PH, Parhofer KG. Low-density lipoprotein-apolipoprotein B metabolism following apheresis: simulation studies of mass changes and tracer kinetics. Metabolism. 1998;47:478-83.

60. Geiss HC, Bremer S, Barrett PH, Otto C, Parhofer KG. In vivo metabolism of LDL subfractions in patients with heterozygous FH on statin therapy: rebound analysis of LDL subfractions after LDL apheresis. J Lipid Res. 2004;45:1459-67.

61. Parhofer KG, Barrett PH, Demant T, Richter WO, Schwandt P. Effects of weekly LDL-apheresis on metabolic parameters of apolipoprotein B in heterozygous familial hypercholesterolemia. J Lipid Res. 1996;37:2383-93.

62. Parhofer KG, Barrett PH, Demant T, Schwandt P. Acute effects of low density lipoprotein apheresis on metabolic parameters of apolipoprotein B. J Lipid Res. 2000;41:1596-603.

63. Parhofer KG. New approaches to address dyslipidemia. Curr Opin Lipidol. 2017;28:452-7.

64. Tsimikas S, Viney NJ, Hughes SG, Singleton W, Graham MJ, Baker BF, et al. Antisense therapy targeting apolipoprotein(a): a randomised, double-blind, placebo-controlled phase 1 study. Lancet. 2015;386:1472-83 The study shows that antisensetherapy can decrease $\mathrm{Lp}$ (a) dramatically (to a greater extent than apheresis). If available it would probably decrease the frequency of apheresis for elevated lipoprotein(a).

Publisher's Note Springer Nature remains neutral with regard to jurisdictional claims in published maps and institutional affiliations. 